Portland State University

PDXScholar

3-2-2018

\title{
"Our inside story is something entirely different" : Cultural Illegibility, Layered Time, and Untranslated Gestures in Fae Myenne Ng's Bone
}

Alexa Climaldi

Portland State University

Follow this and additional works at: https://pdxscholar.library.pdx.edu/honorstheses

Let us know how access to this document benefits you.

\section{Recommended Citation}

Climaldi, Alexa, "'Our inside story is something entirely different" : Cultural Illegibility, Layered Time, and Untranslated Gestures in Fae Myenne Ng's Bone" (2018). University Honors Theses. Paper 520.

https://doi.org/10.15760/honors.525

This Thesis is brought to you for free and open access. It has been accepted for inclusion in University Honors Theses by an authorized administrator of PDXScholar. Please contact us if we can make this document more accessible: pdxscholar@pdx.edu. 
"Our inside story is something entirely different" : Cultural Illegibility, Layered Time, and Untranslated Gestures in Fae Myenne Ng's Bone

by

Alexa Climaldi

An undergraduate honors thesis submitted in partial fulfillment of the requirements

for the degree of

Bachelor of Arts

in

University Honors

and

English

Thesis Advisor

Dr. Marie Lo

Portland State University

2018 
"A city does not divide itself up into parts,

Zone themselves as authentic, real;

It is you who choose to have it served

Skin-deep, or otherwise"

-Karen Cheung, "Skin Deep"

\section{Introduction}

Fae Myenne Ng's first novel, Bone, begins with a suicide and ends with another kind of departure: a migration out of San Francisco's Chinatown. Bone is a story of daughters, of luck, and of finding the right gesture, but it is also a story that, although it speaks from a vantage point that is often highly exoticized and commodified, resists the gaze of literary tourism. ${ }^{1}$ The condition of possibility for this narrative is derived from Ona's suicide, the middle child of three sisters, which hangs over the plot as Mah, Leon, Nina, and the narrator Leila struggle with her decision for doing so. The narrative is told from the perspective of Leila, the eldest daughter, and is structured by a series of layered retrospective vignettes that exist outside of linear time. The Leong family and the intricacies of their familial structures as well as their interaction with the world of San Francisco's Chinatown are presented through Leila's recollection of those memories; but her narration is often riddled with questions and concepts that are raised but never fully and explicitly answered. In doing so, the narrative resists the assumption that language and storytelling are unmediated methods in understanding a culturally legible Asian American experience. Often, the recall of Leila's memories are highly contextual and do not allow for complete access to cultural legibility for a reader who is not familiar with the cultural or linguistic signs. Through the novel's larger placement within the genre of Asian American

\footnotetext{
${ }^{1}$ See Wong, especially pages 254 and 255 , for an analysis of this trend.
} 
fiction, and the opaque narrative tactics such as the layered and non-linear narrative and linguistic and gestural illegibility, Leila recalls and cites her memory in ways that obscure the reader's ability to excavate what is culturally legible within the text, and in doing so, calls into question the conceit that language and narrative are unmediated methods of rendering a minority experience as consumable.

In David Palumbo-Liu's introduction to The Ethnic Canon, multiculturalism is seen as a conceit that allows for the insertion of ethnicity and the Other without critiquing "The ideological apparatuses that distribute power and resources unevenly among the different constituencies of a multicultural society" (2). In the literary canon, texts written by authors of color are viewed as useful because of the glimpse into their culture that they provide, similar to an ethnography, as contrasted by hegemonic American culture. White audiences, in order to have "learned something" from the text, need the stories of the marginalized be both didactic and realistic, in that readers expect to be taught something, but also these teachings are expected to be in line with what they have already come to expect from a certain set of stereotypes concerning the culture at hand. Among texts that are racialized by their authorship or by their content, the utility of Asian American literature as a genre functions under the assumption that literary texts are a conduit for understanding an authentic and unmediated depiction of that experience. In Bone, the narration resists this by letting the stories and events live within the liminal; to exist without extensive explanation, and to resist cultural legibility through an atemporal, at times untranslated, and fragmented narrative.

Because of the interest in multiculturalism in the contemporary moment, approaching a text that does not easily lend itself to the level of transparency required for a general American 
audience is a question of reading practice and consumption. To pull the text out of the realm of mystified aestheticization requires a level of critique and reading "against the grain" to allow for an understanding of the work as it functions within the genre, and the systems of power and historical context that are the condition of possibility for the story itself. Because Leila's narrative does not give us the same kind of satisfactory "authentic" storytelling that we are taught to expect from Asian American literature, it troubles the notion that the reader can aestheticize the text without reconciling the systematic forces at play in creating that experience, and calls into question the conceit that there is "one" story of Chinese American identity that is static and singular. Similarly, history is viewed as singular and linear, and too often tries to claim itself as such. Donald Goellnicht in his essay "Minority History as Metafiction: Joy Kogawa's Obasan" states that "if language constitutes reality, then in speaking about itself, this type of fiction speaks about the world... History- both private and public- is discourse; so too is fiction" (290). In analyzing the way in which linear time and language are mobilized throughout this text to do the work of both illuminating and concealing certain aspects of both the plot, Bone illustrates the Chinese American identity as one that is diverse, fluid, and contingent.

In Bone, and for Chinese Americans, the question of authenticity reaches outside of the sphere of the literary, and is a concept that has historically been troubled by political, geographical, and legal exclusions, placing their cultural identity, family lineage, and ultimately citizenship into the realm of contingency and denial. ${ }^{2}$ Identity and Authentic representations are themes within Asian American literature that have not just cultural currency, but economic currency as well, such as the placement of Maxine Hong Kingston's The Woman Warrior within

\footnotetext{
${ }^{2}$ For more on Chinese American historical context, see Takaki chapters 3 and 6.
} 
the genre of Autobiography as a way to market the truth value of the work. ${ }^{3}$ Given that the history of Asian Americans, especially Chinese Americans, has been marked by the state's ability to use legal language to exclude and discriminate, Asian American literature too seems to be troubled by similar issues of language in relation to identity and authentic representation. Readers expect the literature to be an authentic representation of this minority experience, as if some nugget of truth could be found beneath the prose of the novel; but this interpretation implies that there is a direct relationship between language and truth. The concept of language and its ability to authentically represent is problematized through various forms, the most direct being Leon's “reconstructing” of his own identity. His crafting of his identity, and his need for it to be believable, is made possible by the political exclusions put in place making immigration nearly impossible for Chinese Americans. Although Leila is a Chinese American woman who spent her childhood in America, the effects of Chinese exclusion continue to be stitched through the framework of her family. In a text where identity and authenticity are at stake, the resistance to easily identifiable and compartmentalized depictions of life in Chinatown incites a more complex understanding of the social contingencies that this text produces and is produced by.

\section{Cultural Legibility and Authenticity}

To say that something is authentic is to say that it is what we say it professes to be; that it is faithful to an original and is a reliable and accurate representation. ${ }^{4}$ Debates concerning authenticity when it comes to work produced by Asian American writers have haunted the genre

\footnotetext{
${ }^{3}$ See Wong for a more in-depth analysis of the placement of Kingston's The Woman Warrior within the context of autobiography

${ }^{4}$ For more information on authenticity, see Somogy Varga and Charles Guignon in The Stanford Encyclopedia of Philosophy.
} 
of Asian American fiction in part because of the tendency for readers, particularly white readers, to project the label of autofiction onto works of non-white authorship. Publisher's Weekly calls the novel a "believable journey through pain to healing, exposing the emotional scars of its characters as they try to survive." The Los Angeles Times describes Bone as placed within the tradition of Chinese American fiction, like Amy Tan or Gish Jen, which are often applauded for their realism and their evocation of emotion. The article, titled "A Gritty Story of Assimilation" states that "In each national variation on the American novel of ethnic assimilation and estrangement, there is the battering of the old country by the new... In none of them does the family loom so large as in the work of Chinese American writers."

In both of these reviews, the pressure for Bone to perform as what hegemonic society would describe as "Chinese American" is central to the quality of the reading experience; Bone is not just a fictional story about Chinese Americans, it is a "believable" one. The concept of the journey from old to new, from origin to unfamiliar territory, relies on the idea that there is a linear progression of the narrative of assimilation, and that it somehow involves "battering" the old, outdated practices of the origin with the new, modern practices of America. I would argue that in Bone, there is no "battering" of the old, no beating it into submission in order to assimilate. The cultural actions and signs that are enacted within the novel are neither Chinese or American, and instead embody the liminal space that is created when one is subject to being placed as a foreigner in the land that they live in without sacrificing the practices that they grew up with. Finding the right gesture for Leila is not always about finding what the "right" or "traditional" way of doing things is, and instead seems more to be about producing the right gesture given the social and political context of the world that she lives in. The promise of a 
Chinese American woman author reflected in her Chinese American woman narrator seems enticing for white readers; they want to believe that Bone is giving unmediated access to an experience that they cannot name, revealing a history that had been left out of the linear account. Instead, the narrative resists the kind of cultural legibility that would produce a more direct interpretation of life that could be compartmentalized as Chinese or American in San Francisco's Chinatown.

A recent example of this expectation of the author comes from the controversy around Bill Cheng's debut southern gothic novel titled Southern Cross the Dog that was published in 2013. A New York Times article reviewing the novel is titled "Imagining a Past That Isn't His Own", and makes it a point that "Mr. Cheng is a 29-year-old Chinese-American from Queens. Until this month he'd never set foot in Mississippi." Cheng's novel concerns a Mississippian black musician, and without fail, reviewers made it a point to illustrate the difference between Cheng, the author, and the protagonist in his work. The irreconcilability of Cheng's status as a Chinese American and the scope of his work concerning a protagonist who is not also Chinese American, speaks to a set of standards and expectations that many readers have towards Asian American writers, or of stories that speak to experiences outside of the charm circle of white-dominated narratives. While white writers are often lauded for their ability to be imaginative when writing about experiences or countries that they have no experience in, Asian American writers are held to a perceived personal scope of experience; one that allows for a small amount of improvisation from a certain set of cultural stereotypes.

\footnotetext{
${ }^{5}$ Garner goes on to state that there is a sense of "ventriloquism" to Cheng's work, questioning the authenticity of his attempt at fiction.
} 
In a similar vein, Maxine Hong Kingston's The Woman Warrior is a text that has also often been troubled by its transition from non-fiction to fiction and also by its relationship to the author. Originally published as a work of non-fiction autobiography, The Woman Warrior's publishing strategy capitalized on the assumption that white readers believed in the promise of truth and authenticity from the autobiographical genre. More recently, The Woman Warrior has been published under the genre of "fiction", however it still maintains its utility as a work that is included in canons because of what it can offer; a "report from the pit" as Baldwin states in his 1949 essay "Everybody's Protest Novel". The novel's readership remains lively, and is at home on the syllabi for numerous college courses; it is a book that, despite its departure from the realm of non-fiction, has still maintained its velocity as an important work within the canon of Asian American literature. The Woman Warrior is a book that, through its status as an autobiography, white readers come to believe that they know or understand a version of Chinese American reality, and that autobiography delineates authenticity because it is believed to be a direct representation of a real experience. Works written by Asian American writers do not need to be labeled as autobiographical because the work never seems to be able to elude the ethnicity of the author. With its status as minority literature, white readers want to believe that they are taking part in a narrative that gives voice to an experience that they do not yet have contact with, and the realm of the novel and the medium of text makes this indulgence "safely ensconced in the social arena... This report from the pit reassures us of its reality and its darkness and of our own salvation" (Baldwin 19). ${ }^{6}$ Literature can illustrate experiences that one might have little to no

\footnotetext{
${ }^{6}$ Baldwin further states that the act of reading the protest novel is a vital part of the American scene, in that it ramifies the hegemonic structures that we believe are "necessary" in society. Instead of being critical of these works, the passive reception of the production of minority literature is one part of the issue that Baldwin articulates on page 19.
} 
contact with in their own life, which provides a reminder of the experiences of the marginalized Other, however the medium of literature also seems to produce a kind of voyeurism or ethnographical lens into the narrative, where the act of reading alone seems to be the remedy to understanding the plight of another.

As times become more politically tumultuous, the nation often turns to unity to resolve them. Diversity and exposure to minority literature seems to function as a means to manage issues of race, class, gender, and labor inequality that are produced by late capitalism, which has distributed benefits disproportionately. The recent interest in multiculturalism is one that has been made in the interest of pluralism, and functions because of the belief that the two terms can be used interchangeably. Pluralism in this sense functions under the idea that diversity is valued only if that diversity is underneath the umbrella of a national identity that everyone adheres to; multiculturalism on the other hand posits that the values and interests of the minority hold the same weight as those of the majority. ${ }^{7}$ This is not to say that multiculturalism cannot do the work of making readers aware of different experiences, but rather to require a more critical lens when approaching literature that dominant structures have been deemed "non-American". In Immigrant Acts, Lisa Lowe states that:

If the nation proposes American culture as the key site for the resolution of inequalities and stratifications that cannot be resolved on the political terrain of representative democracy, then that culture performs that reconciliation by naturalizing a universality that exempts the "non-American" from its history of

\footnotetext{
${ }^{7}$ See Butera for more information on differentiation between multiculturalism and pluralism.
} 
development or admits the "non-American" only through a "multiculturalism" that aestheticizes ethnic differences as if they could be separated from history (9).

Here, multiculturalism is posited as a way to include the "non-American" by way of aestheticization without historical representation. Multiculturalism is the winning chess move of American capitalism; it tries to embrace difference as if it did not produce those differences in the first place, while also claiming to give visibility to those who are deemed "non-American" by allowing them to take up marginal space. As Foucault notes in The History of Sexuality, if “'marginality' is being constituted as an area of investigation, this is only because relations of power have established it as a possible object... if power is able to take it as a target, this is because techniques of knowledge were capable of switching it on" (98). This is to say that, although systems of power have produced subjects as "marginal", it does not mean that the agency is completely out of the marginalized subject's hands. In a sense, it is how we are able to read and understand the context of marginalized works and exposing the framework with which they are subjected to that allows for "techniques of knowledge" to serve a dual purpose. No art can exist within a vacuum, and it is our need for having works serve as authentic representations of the experience that they aim to portray that can often separate aesthetic analysis from historical context. Bone structurally resists our ability to read the work as outside of its history troubled by immigration and identity politics through its atemporal form. History is known as linear, as a progression from the uncivilized to modernity, and to produce a narrative that denies a story in straight time troubles the perception of linear time as historical or realistic. In an interview with Angel Shaw from Bomb magazine in 1993, Ng states that 
"It was very important for me to ask questions but not dictate the answers. It was very important to respect the reader...Reading is a very private experience and the reader brings their own worlds of insights and possibilities to the book. For example, Ona, the middle daughter's suicide. Why did Ona do it? I wanted, in the book, to honor Ona's decision, to talk about the possibility of understanding that her death is a private moment, a very intimate moment. It's very hard to honor a decision like that. But it's very important to suggest that there is a way of doing so."

Bone sets the reader up to do the work of considering the different social and political factors that have shaped the lives of the Leong family by not setting them up completely, making the distance between what is known in the text, the memories narrated by Leila, and what the reader relies on from their own body of knowledge the crux of how the interaction between aesthetic and historical are set up. Unlike how we come to expect minority fiction to function, where the experience is both didactic in that we expect it to teach us something about the culture at hand, but also that it is realistic and believable, Bone leaves questions unanswered, words untranslated, stories unfinished, and linear time unutilized, eluding the reader's ability to experience the novel as a story existing outside of its historical past.

For the ethnic literary canon of which Bone is a part of, the promise of authenticity is what contextualizes their utility as works of Asian American literature within the larger scope of American literature. As Arnold Krupat puts it, "Texts bound by the real insist upon an epistemological status different from works of the imagination in which the real is more nearly hypothetical" (25). Bone does indeed take place in reality, in San Francisco's Chinatown, including landmarks to illustrate its place in the "real" world. Real or imagined, we read the 
landmarks as true places, as things that tie the narrative to reality, because of their enclosed space in such an iconic location. The novel opens with a declarative "We were a family of three girls." (Ng 1), and remains in past tense for the majority of the novel, as if Leila is recounting completed events in reality. Despite its grounding in the "real", Bone is a text that takes great liberties in narrative structure and style, with omissions and deflections, and memories that drift through the narration like flotsam and jetsam, objects of the past that are brought back up into the present. We expect works like Bone to present themselves in a straightforward way so that we can feel comfortable with understanding the work. Bone might not give us the "authentic" or straightforward representation that we expect in that it does not answer all of the questions for the reader by not offering a narrative in straight linear time, which leaves the reader to have to do the work of filling (or not bridging) the gap between what has been said on the page and what they already understand as culturally legible, but it also might be the most authentic for exactly those reasons.

\section{Layered and Temporal Form}

Authenticity and being "true to an origin" means retracing the past to prove a projection of that origin as real. To begin to talk about Bone in relation to ideas of authenticity and originality, the structure of the narrative and the medium of recollection and memory formation are sites through which the idea of authenticity as a direct and linear association to its origin is troubled. Bone is a novel that relies on the use of memory, of the retracing of an event in the past, or of giving shape to an original event from the past. Because it is a text that is indirectly or directly is invested in the origins of things in the form of immigration, original or fabricated 
identity in the case of the Paper sons, the origin of Ona's suicide, and the return of Grandpa Leong's bones to China, the concept of finding the original, or returning to the original seems prevalent in the text, even given that it feels as if the narrative is circling a center that is not there. One of the main reasons that this is achieved is through the atemporal narrative. Instead of an indiscernible future, the narrative digs into the past, troubling the linear temporality of historical texts.

Lisa Lowe's analysis of the narrative of history in Bone from Immigrant Acts in the Chapter "Decolonization, Displacement, Disidentification: Writing and the Question of History" addresses the ways through "the material histories that have been subjugated or erased by" the Historical narrative as it is linear and progressive. The temporality that $\mathrm{Ng}$ employs in the narrative is one that acknowledges what is left out of the forward march of History as it moves from uncivilized to civilized, from traditional to progressive. Lowe notes that $\mathrm{Ng}$ does Not seek...to find and represent an essential authenticity, to articulate the past "the way it really was." Rather...they "seek to brush history against the grain." If historical narrative is, as Benjamin suggests, a narrative that has "empathy for the victor," the material memory of the unvictorious is not simply repressed by that narrative; it dialectically returns. (126-7)

This brush with history and hegemonic narratives is evident throughout the novel in its form, in that it distances the reader's ability to feel as though the events in the novel can be traced to a single origin; the "dialectical return" that Lowe notes of is structured around Ng's use of layered memories to tell the story of the Leong family. The voice of the law and hegemony that comes 
through in the novel is one that is grounded in its ability to understand the world as linear and ordered. The policeman at the site of Ona's death is one such example of this, where Leila states: He didn't get it. He was looking at the typical stuff. He was looking at now...I could have given him Leon's explanation that it was because Grandpa Leong's bones weren't at rest...But I didn't say any of this; it wasn't anything he could use for his report. (Ng 139)

Here, the incompatibility between the paradigm of factual knowledge and superstition is displayed through the voice of law, and ultimately, what is culturally legible to the officer. Because superstition and luck are not concepts that are readily accepted within the realm of law, or rather, the realm of organized cause and effect as necessitated by hegemonic American society, the reasons for Ona's suicide can never be distilled down or sanitized enough for the police report, and also for the reader. Dominant culture itself is often troubled by the idea of suicide, because it has no place in logic, and the "cause" of the death can never truly be pinned down because of the multiplicity of the self. At the same time, dominant culture insists that there must be a cause for an effect, a preceding event for an outcome. By "looking at now" the police officer is missing something vital; all of the fragments and simultaneous moments in the past that had affected Ona. Leila insists on a narrative invested in the past, or rather the movement of "Forward and forward and then back, back" (Ng 145).

Ona's suicide is narrated in a similar manner, and although Leila cannot narrate exactly what had occurred, the way that she is able to make manifest Ona's death is through her body as it is both static and moving through time. 
I saw Ona falling and falling. She wouldn't stop: it was like movement and no movement. I sipped. The water brought my breath back. I was suspended between air and water, breathing and crying... Time rushed ahead, swelling, and then snapped still, stopping. (Ng 135)

Ona's death is so continual that it gives the illusion of stillness. Death itself is a concept that seems to be over an in instant, but for Ona and her family, the waves of influence are very much so present and urgent, existing in both the past and the present. Ona is nearly always described as "falling" and "flying" throughout the novel, never landing. Her travel is continuous, and indicates the kind of guilt that is associated with knowing too much. Leila states that "I wanted to remember Ona alive, whole. I didn't want to see her broken.” (Ng 153). Ona's existence is continual because it has to be; she still exists for the Leong family. This idea of the past always being stitched within the present moment is one that occurs throughout the text: "Relaxed, I thought there was a connection. Johnnie Walker then and Johnnie Walker now.” (Ng 29). Memory as a site of recall seems to be interpreted as something that can only occur in the past, as a way to reminisce. For Leila, memory serves to be both an action in the present, but also as a way of articulating the ways in which we understand the past as naturalized history. Lowe states that

The "past" that is grasped as memory is, however, not a naturalized, factual past, for the relation to that past is always broken by war, occupation, and displacement. Asian American culture "re-members" the past in and through the fragmentation, loss, and dispersal that constitutes that past. (29) 
The "factual past" that is often taken for granted often seems to not allow for marginalized voices to occupy the same amount of space, and in the case of Asian American literature, imperialist structures have made their mark on the inner forms through an active engagement with the past as a site for not just re-membering the past, but also re-imagining the ways that we interact with the past through fragmentation and loss. The past is a space that cannot be wholly or univocally translated. By structuring the narrative around a series of memories in a nonlinear way, Bone resists the conceit that past and present can be narrated in linear temporalities and be authentic to an original, and instead offers a structure through which the contours of the past can be felt, spatialized, and understood in terms of multiplicity.

\section{Linguistic Illegibility}

The way that Leila posits herself in relation to the language that is used to narrate in the text and the language that is used by her in both Chinese and English illustrates a distancing of not just the two languages, but the distance between the text and the reader as well. Leila's position at her job is described as "being the bridge between the classroom teacher and the parents." (Ng 16). As a bridge between the teachers and the student, between America and Chinatown, between English and Chinese, she balances between the liminal space of language and communication. Her role makes her feel as if she is "doing a bit of a missionary number" (Ng 16) when speaking to the parents about their children; Leila is reporting to and from these different spheres of domesticity. The role of the bridge is one that Leila has taken on in multiple forms, between Mah and Leon, between Chinatown and San Francisco, but also between the reader and the text. When we, as readers, are faced with a narrator who openly laments the task 
of translation with Mah and Leon on multiple mediums other than the strictly linguistic, how do we reconcile the distance produced by our inability to understand the "language" of Chinatown?

Leila acts not only as the narrator of the novel, but also as a character whose voice and words are used for the benefit of Mah and Leon. Words and their meaning have a heavy burden for Leila: "I hated standing in the lines: social security, disability, immigration. What I hated most was the talking for Mah and Leon, the whole translation number. Every English word counted and I was responsible... Every English word was like a curse" (Ng 17). The stress of translation is often emphasized throughout the narrative, as the anxiety of words said, words unsaid, and gestures uncommunicated seems to be at the locus of of the main tensions in the text. One of the largest propelling factors to the plot is the unanswering of Ona's suicide; but this too is an issue of misunderstanding, of not performing the right gesture, of not speaking the right words at the right time. This concern is echoed in Leila's question, "If I'd been living on the Alley, would I have said the right word?" (Ng 46).

Leila resists the performance of what Sau-Ling Wong calls the "literary equivalent of a guided Chinatown tour" (262) in part because of her lack of clear cultural translation and of her clarity in articulating the difficulty of translation both linguistic and gestural. For white readership, this goes against how Asian American fiction has been brought into the literary stage: If the narrator cannot represent their culture because they will not give access to understanding the manners and mores of the Chinese American community, then what becomes the utility of the text? Wong states that:

Given the distressing tendency of white readers to confuse Chinese Americans with Chinese in China, and to attribute a kind of ahistorical, almost genetic, 
Chinese essence to all persons of Chinese ancestry regardless of their upbringing, the pressure on American-born writers to likewise "represent Chinese culture" is strong. (262)

The expectation of transparency that we expect narrators to perform as we read their narrative is one that is bred from the idea that not only do is there an expectation of this kind of explanation from Asian American bodies, there is an expectation that narrative should also allow up all of the background knowledge and create a cultural roadmap to understanding the narrator's culture. Both of these conceits do not acknowledge the arduous task of not just the act of translation itself, but also the pressure of marginalized bodies to be open to "reading", that is, the idea that the white America has some kind of ownership over the "meaning" of those narratives.

Linguistic signs and meaningful gestures are what makes a text both culturally illegible and mystified, considering that in Bone and for other Asian American narratives, the language of the racial Other is often utilized for realism and also as a necessary means to articulate the code switching between languages. Often works within the genre of Asian American fiction have a kind of "translation" effect; taking one word or phrase and offering up a direct translation to the reader, who is assumed not to have known the meaning of the word. Leila resists this in her narration, begrudgingly giving the reader the definitions or omitting the definitions completely. As Leila talks about the building that Ona committed suicide from, she states: "Nam means south and ping yuen- if you want to get into it- is something like "peaceful gardens." We call it the Nam. I've heard other names: The Last Ping, The Fourth Ping. For us, the Nam is a bad-luck place, a spooked spot." (Ng 14). Leila's attitude and annoyance towards translating what the 
name of the building means in English disrupts the idea of her as a tour guide, and troubles the notion that as the narrator, she is obligated to explicate cultural terms so that they are easily digestible to a white audience. In addition to this attitude, her description is not concrete, it is an approximation. As opposed to the direct translation model, where each word or phrase has a direct English equivalent, Leila provides not only a vague english answer, but also the different names that have been placed on the place itself. This troubles the idea of a singular translation; multiple meanings for one name exist, and in this case, the space itself has garnered multiple meanings from the community in multiple contexts. The disconnect between the naming of the place as a "peaceful garden" and the association that building has as project housing, forces the reader to reconcile the oriental aesthetic of the name placed upon it and the social implications of its utility. This is to say, that the relationship between the purely aesthetic is one that cannot be understood without social context, unlike how Chinatown's cultural spaces and objects are often read as apolitical and ahistorical.

Because Bone is a text that is invested in the implications of silence and omission, vocality and voice are also at stake. Historically, Asian Americans have been silenced out of the political terrain in part because of troubled immigration histories. To exist in a society that demands assimilation, while also putting freedom and political consciousness in terms of vocality and "speaking out", one's own "foreign" language becomes a site of silence because of its incongruence with hegemonic America. The way that Bone utilizes silence seems to redefine the way we view silence as a passive act, as a practice imposed on bodies that would otherwise speak out; silence is a medium of communication, a way for language to go beyond the spoken and into the gestural. In addition to making the linguistic terms illegible or approximated and 
resisting the flashcard effect of translation, much of the meaning made in Bone is through gestures and acts that relay meaning and communicate emotions and signs to other characters. These gestures, just as with the linguistic terms, are often not clearly outlined, and are further complicated by its placement within the medium of text rather than image; gestures as language seem to function more efficiently through the visual, and are obscured by text.

Language in a linguistic sense does not entirely account for the methods of communication in the narrative, as gestures can function as a language as well. The gesture itself is an action that has meaning through repetition and cultural context, in that it must not just be repeated for it to be understood, it must also be understood by all parties involved. Theorist Judith Butler describes this in terms of "performativity". Butler states: "the performative is not merely an act used by a pre-given subject; rather, it is one of the powerful and insidious ways in which subjects are called into social being... The social performative is a crucial part not only of subject formation but of the ongoing political contestation and reformulation of the subject as well" (44). The gestures that one performs are not an innate part of one's racial or cultural identity, but instead are a constant reformulation and reshaping of that identity. Performing gestures is one way to trace back the past into the present moment, because it relies on the repetition and citation of the same gesture throughout history for the act to gain its meaning. In Bone, the embodied performances of funeral rites, of crafting paper identities, and of telling stories all encompass the different ways that gesture is used to not just participate in cultural practices that inform Chinese American identity, but also as a means to redefine and recontour the categorization itself. 
The acts embodied are ensconced within the landscape of America, and resist the kind of backwards connection to China in cultural practice and ritual that would make the text function as an ethnography for readerly consumption. Acts in the narrative illustrate just how broad the term "Chinese American" encompasses. As the association man tells Leila, "Bow to the family headstone, its all the same, the right gesture will find your grandfather." (Ng 78). Reperforming acts finds answers in this text, and the act of "telling" seems to be one method through which identity is produced. Mah states this after finding out about Leila's marriage, which is displayed on the page in a poetic structure:

"Just like that.

Did it and didn't tell

Mother Who Raised You

Years of work, years of worry.

Didn’t! Even! Tell!" (Ng 22)

Telling, here, becomes the site and act that is prioritized, just as Grandpa Leong had said that "the best way to conquer fear is to act. Open the mouth and tell." ( $\mathrm{Ng} 21)$. Storytelling itself is an act, and seems to be central to the production of meaning-making in the text. Mah speaks, or "tells" in poetic form here, the trouble of not telling. This again echoes the anxiety around the weight of words, of words said and not said, and the different outcomes that come from each speech act. In addition to the anxiety felt around words and language, Mah's commandment of English is depicted as poetic, as artful. Often, white readers tend to read broken English as a hindrance, as an indication of someone's inability to grasp the language, and as an indication of their intelligence level. Presenting Mah's language as artful and as calculated through the 
medium of poetry, Leila posits her language as meaningful and impactful, as opposed to how the broken-english stereotype is typically utilized, and reimagines how words can be crafted to illustrate their power and their impact, as opposed to their lack.

\section{Conclusion}

Outlining the resistance that can be found in the inner forms of Bone brings up questions of an ethical reading practice. As readers, we are looking in, looking for clues and looking to understand the lives of those we read about. Leila speaks of this looking in, where she states:

"This is what tourists come to see. I felt a small lightening up inside, because I knew, no matter what people saw, no matter how close they looked, our inside story is something entirely different. I knew the dangers of closing up, but I didn't care. Right then, I didn't want people looking in at us." (Ng 145). Leila addresses the fact that no matter how hard we look, no matter how much we think we might know about their story, it will never completely reveal itself. As readers, how do we come to reconcile a text that tells us not to "look in", and is it possible to have a close reading practice that is not invasive? For Asian American literature, this move toward resisting legibility illustrates a consciousness of the implications of the genre as ethnography, and instead forces the reader to reconcile their status as viewers into their community, as opposed to feeling as if they can empathize or understand completely the experiences of the characters within the narrative. Leila sets up a firm barrier between the in-group and the out-group, and instead, paints a fragmented portrait of a multivalent Chinatown that cannot be pinned to any one singular story. 
Part of the act of close reading is to uncover the unintelligible, to make sense of and name that which we can understand through the medium of text and language. First person narrative is a strong medium through which the reader feels an immediacy to what is occurring within the text, a close proximity to what is happening in the narrative. Particularly in Chinese American fiction, the promise of a first person Chinese American woman narrator written by a Chinese American woman is that the narrative is somehow directly representative of the author's experiences, and is utilized as an unmediated glimpse into the lives of people within Chinatown. However, for Leila, this closeness is distanced by the lack of a linear, straight time structure and her use of language and gesture as a means to let the meanings of words live within the liminal without over explanation. This distance between the reader and the text creates a didactic that produces the kinds of reading practice that can be most productive in reconciling the difference between what is known and what is on the page for the reader. Bone refuses to be purely aesthetic, and although it is a beautifully crafted text, the narrative is one that cannot exist without also understanding the social forces and structural powers that have placed categorization, authenticity, and cultural legibility at stake. 


\section{Works Cited}

Baldwin, James. “Everybody's Protest Novel”. Notes of a Native Son. Beacon Press, 1955.

"Bone/ Fae Myenne Ng". Review of Bone by Fae Myenne Ng. Publisher's Weekly, 4 January 1993. https://www.publishersweekly.com/978-1-56282-944-5. Accessed 15 February 2018.

Butera, Anita Christina. "Assimilation, Pluralism and Multiculturalism: the Policy of Racial/Ethnic Identity in America." Buffalo Human Rights Law Review, vol. 7, 2001, pp. $1-31$.

Butler, Judith. Gender Trouble Feminism and the Subversion of Identity. 2nd ed., Routledge, 1999.

Eder, Richard. "BOOK REVIEW: A Gritty Story of Assimilation: BONE By Fae Myenne Ng ; Hyperion; \$19.95; 224 Pages”. Los Angeles Times, 14 January 1993. http://articles.latimes.com/1993-01-14/news/vw-1322_1_fae-myenne-ng. Accessed 15 February 2018.

Foucault, Michel. The History of Sexuality. 1st American ed., Pantheon Books, 1978.

Garner, Dwight. "Imagining a Past that isn't His Own: 'Southern Cross the Dog', a Novel by Bill Cheng". Review of Southern Cross the Dog by Bill Cheng. New York Times, 21 May 2013.

Goellnicht, Donald C. “Minority History as Metafiction: Joy Kogawa's Obasan.” Tulsa Studies in Women's Literature, vol. 8, no. 2, 1989, pp. 287-306.

Lowe, Lisa. Immigrant Acts : on Asian American Cultural Politics. Duke University Press, 1996.

Ng, Fae Myenne. Bone. HarperCollins Publishers, Inc. New York, 1993.

Palumbo-Liu, David. The Ethnic Canon Histories, Institutions, and Interventions. University of Minnesota Press, 1995.

Shaw, Angel. Interview with Fae Myenne Ng. Bomb Magazine, 1 April 1993. 
https://bombmagazine.org/articles/fae-myenne-ng/. Accessed 3 January 2018.

Takaki, Ronald T. Strangers from a Different Shore : a History of Asian Americans. Penguin Books, 1990.

Varga, Somogy and Guignon, Charles, "Authenticity", The Stanford Encyclopedia of Philosophy (Fall 2017 Edition), Edward N. Zalta (ed.) https://plato.stanford.edu/archives/fall2017/entries/authenticity.

Wong, Sau-ling Cynthia. “Autobiography as Guided Chinatown Tour? Maxine Hong Kingston's The Woman Warrior and the Chinese American Autobiographical Controversy". Maxine Hong Kingston's The Woman Warrior : a Casebook. Oxford University Press, 1999. 